\title{
A Comparison of the Usability of a Standard and an Age-Friendly Smartphone Launcher: Experimental Evidence from Usability Testing with Older Adults
}

Short title: Comparison of Standard and Age-Friendly Smartphone Launchers

Andraž Petrovčič, Ph.D., Mojca Šetinc, M.A., Tomaž Burnik, M.A., Vesna Dolničar, Ph.D.

This article was originally published in International journal of rehabilitation research 41(4): 337-342 by Wolters Kluwer Health, Inc. The publisher's version of this article is available at: https://doi.org/10.1097/MRR.0000000000000307.

Suggested citation:

Petrovčič, A., Šetinc, M., Burnik, T. and Dolničar, V. (2018). A comparison of the usability of a standard and an age-friendly smartphone launcher: experimental evidence from usability testing with older adults. International journal of rehabilitation research 41(4): 337-342. DOI: 10.1097/MRR.0000000000000307.

University of Ljubljana, Faculty of Social Sciences, Kardeljeva ploščad 5, 1000 Ljubljana, Slovenia, andraz.petrovcic@fdv.uni-lj.si, mojca.setinc@fdv.uni-lj.si, tomaz.burnik@fdv.uni-lj.si, vesna.dolnicar@fdv.uni-lj.si

Address correspondence to:

Andraž Petrovčič, Ph.D.

University of Ljubljana

Faculty of Social Sciences

Kardeljeva ploščad 5

1000 Ljubljana

Slovenia

E-mail: andraz.petrovcic@fdv.uni-lj.si

Phone: +38615805 200, Fax: +38615805101

Conflicts of interest: None declared.

Source of funding: The research leading to these results has received funding from the Slovenian Research Agency (Grant Nos. L5-6818, L5-7626, P5-0399). 


\begin{abstract}
Age-friendly smartphone launchers are tools designed to enhance smartphone handling among older adults with cognitive and functional limitations. While evidence exists about the positive effects of age-friendly smartphone launchers on older adults' usability performance in general, little is known about how the design and interface complexity of these launchers affect their interface usability effectiveness and efficiency when compared to standard Android smartphone interfaces. Thus, in this study, a randomized crossover experiment involving 50 older smartphone users, aged 60 and above, was guided by the principles of summative usability testing to assess whether an age-friendly launcher performs better than a standard Android launcher performs and to investigate the relationship between the user interface complexity and usability performance of launchers. The results of usability tests in which each participant solved 10 tasks on both launchers indicate that the two tested launchers had comparable effectiveness (i.e., completeness with which participants achieved the test tasks' goals), whereas the agefriendly launcher marginally outperformed its standard Android counterpart in terms of efficiency (i.e., the amount of time used by participants to solve the test tasks). The results also demonstrate that lower user interface complexity is associated with higher effectiveness and efficiency, suggesting that age-friendly smartphone launchers might lead to higher adoption rates of smartphones among older adults if interface designers could reduce their cognitive complexity by limiting the number of steps and alternative paths for task completion.
\end{abstract}

Keywords: age-friendly design, older adults, smartphone launchers, user interface complexity, usability testing 


\section{Introduction}

Smartphones have the potential to promote independent living, active and healthy ageing, the maintenance of social relationships, and a sense of safety and security among older adults (Arab et al., 2013; Doughty and Williams, 2016; Nielsen and Budiu, 2012; Plaza et al., 2011). Their integrated sensors also make smartphones a promising avenue for monitoring health parameters and delivering rehabilitation interventions (Reyes et al., 2018). Smartphone apps have been designed to provide various forms of rehabilitation services, including rehabilitation and assessment tools targeted at a diverse set of health problems and disabilities (Dicianno et al., 2015). For instance, apps exist that help increase physical activity in people with cardiovascular disease (Maddison et al., 2015), that allow for self-managed balance interventions (Reyes et al., 2018), and that foster stroke rehabilitation (Wong et al., 2017). There is ample empirical evidence that interventions that employ rehabilitation apps lead to positive outcomes not only in terms of improved health conditions but also in terms of subjective dimensions related to quality of life (Gandhi et al., 2016; Park et al., 2016; Siegel and Dorner, 2017).

However, at present, understanding of the population-based impact of such apps has been inhibited by the fact that smartphone use is not mainstream among the aging population. In the US, only $42 \%$ of those aged 65 and older ( $31 \%$ of those aged 75 to 79 and $17 \%$ of those aged 80 and older) own a smartphone (Anderson and Perrin, 2017). The uptake of smartphones in Slovenia is even lower, as only $27 \%$ of mobile phone users aged 55 and older own a smartphone (Dolničar et al., 2016a). Moreover, representative survey figures for the US indicate that only $19 \%$ of smartphone owners have downloaded an app to track or manage health, and of those that have, only $16 \%$ are aged 50 to 64 , while $10 \%$ are aged 65 and older (Fox and Duggan, 2013). 
It has been suggested that these lower rates stem from older adults encountering various difficulties in interacting with smartphone user interfaces due to their age-related issues concerning perception, cognition, and movement control (Anderson and Perrin, 2017; Dolničar et al., 2016b; Holzinger et al., 2007; Petrovčič et al., 2018a, 2018b). To enable older adults to exploit the potential of smartphones, age-dependent modalities need to be addressed in the interface design process (Fisk et al., 2009). Launchers that allow for an age-friendly designed user interface within a mainstream smartphone have been developed for this purpose (Balata et al., 2015). They are part of smartphone's user interface, enabling users to customize the home screen and perform other tasks more easily (Petrovčič et al., 2018a). In general, age-friendly launchers are programmed with the aim of reducing the complexity of the smartphone user interface, as a lack of complexity leads to a better user experience for older users (Fisk et al., 2009). In particular, a cognitively complex mobile phone interface can substantially amplify the negative effects of older adults' cognitive and memory deficits on system operation on small-size screens (Ziefle, 2002). For instance, it can diminish the visibility of interaction elements and interface controllers, increase users' confusion and disorientation in menu navigation, decrease the learnability and memorability of the user interface structure, and/or severely limit error recovery (Petrovčič et al. 2018b; Ziefle, 2002; Ziefle and Bay, 2005).

Even though there is promising research underway related to the usability performance of age-friendly launchers (Balata et al., 2015; Dolničar et al., 2016b; Hwangbo et al., 2013; Petrovčič et al., 2018b), no study has yet compared the usability performance of an age-friendly smartphone launcher with that of a standard Android smartphone launcher or explored how the difference in user interface complexity between 
them affects their usability performance. Therefore, the purpose of this study is to fill that gap by addressing the following two research questions (RQs):

RQ1: Are there any differences in task success and task efficiency between a standard Android and an age-friendly designed launcher?

RQ2: What is the relationship between the complexity of the user interface on a standard Android and an age-friendly designed launcher, and what is the difference in their usability performance in terms of task success and task efficiency?

\section{Methods}

\subsection{Procedure and design}

To answer the two RQs, older adults completed two summative usability testing sessions (Lewis, 2012) in a crossover experimental design in which participants were randomly distributed into two groups of equal size. The first group first carried out the usability testing session on the Android launcher and then tested the GoLivePhone, an age-friendly designed launcher. ${ }^{1}$ Conversely, in the second group, the GoLivePhone launcher was used first, followed by the Android launcher.

Test sessions conducted in summer/autumn 2017 included three parts. In the first (pre-test) part, participants were provided basic information about the study. Each participant signed a consent form and answered a short pre-test questionnaire about their socio-demographics and smartphone proficiency. In the second (test) part, each

\footnotetext{
${ }^{1}$ For a more detailed description of the GoLivePhone launcher, see Dolničar et al. (2016b). The selection of the GoLivePhone launcher was informed by a study showing its top-ranking performance among agefriendly launchers in terms of congruence with age-friendly design guidelines for mobile phones (Petrovčič et al., 2018a).
} 
participant was given five minutes to familiarize him/herself with the launcher. Then, s/he was asked to complete ten tasks within a time limit ranging from three to four minutes. ${ }^{2}$ In the third part, once the session for the first launcher was completed, each participant filled in a short post-test questionnaire about his/her subjective evaluation of the launcher's usability. Afterwards, the second and third parts of the test session were repeated by the same participants but this time for the second launcher.

The actions of the participants were recorded using a document camera and Morae Usability Testing software (TechSmith, 2018). Real-time streaming of the smartphone screen on the computer was used to observe participants during task execution, to identify errors, to determine task completion, and to make other field notes.

\subsection{Apparatus}

All participants carried out the tasks on Android and GoLivePhone launchers using the same type of device, a Samsung Galaxy A3 (2016) with a 4.7-inch $720 \times 1280$-pixel touchscreen display and Android OS version 6.0.1 (Marshmallow). When conducting tests on Android, the device was set to the factory settings.

\subsection{Sample}

Non-probability purposive sampling was used to recruit 50 older smartphone users aged 60 years or older. Participants were recruited from five institutions, working in the field of life-long learning and inter-generational cooperation in Slovenia. The sample was $66 \%$ female, $44 \%$ of the participants were aged 61 to 65 , and $10 \%$ were aged 76 or older. Fiftyfour percent of participants had some university education. Almost all (94\%) used their smartphone every day or almost every day, $64 \%$ had started using a smartphone three years ago or earlier, and $88 \%$ were users of an Android smartphone.

\footnotetext{
${ }^{2}$ Time limits were set because participants had previous experience with smartphone handling.
} 


\subsection{Test scenario}

Tasks in the testing scenario were divided into four groups, depending on their contents, the type of feature, and their complexity (Table 1). The order of the task groups was assigned to participants randomly and remained the same for both launchers.

\section{[Table 1 to be placed here]}

\subsection{Measures}

\subsubsection{Launcher Usability Metrics}

The usability performance of a launcher was evaluated based on its effectiveness and efficiency. Effectiveness is the accuracy and completeness with which a certain goal is achieved by the user, whilst efficiency refers to the amount of resources a user expends to achieve a certain goal (ISO, 2018) and, generally, denotes the deviation from what is expected to be an optimal user behavior (Sonderegger and Sauer, 2010). In this study, effectiveness was measured using the metric of task success which was calculated as the percentage of participants who successfully completed the task (Albert and Tullis, 2013). Efficiency was determined by the metric of task efficiency that was calculated as the average of proportions between a participant's task success and the time spent on the task across all valid subjects ${ }^{3}$ solving a task (Sergeev, 2010)—with higher values indicating greater task efficiency.

\subsubsection{User Interface Complexity Matrix}

Drawing on Campbell's (1988) notion of task complexity, we defined the User Interface Complexity Matrix (UICM) in this study. The UICM consists of two dimensions: (1) the minimum number of actions (taps) that needs to be taken to achieve the goal along the

\footnotetext{
${ }^{3}$ Valid subjects were participants who at least attempted to complete the task.
} 
optimal path in the user interface (Endsley, 2011) ${ }^{4}$ and (2) the presence of multiple potential ways to arrive at a desired end state (i.e., to achieve the goal) in the user interface. Based on these two dimensions, a $2 \times 2$ matrix with four sub-divisions can be drawn, as illustrated in Figure 1. The dimension "length of optimal path" was divided according to the median value of the number of actions along the optimal way for all 10 tasks in both launchers. Tasks consisting of five or fewer actions were defined as "Simple," whereas tasks consisting of six or more actions were characterized as "Complex." Likewise, the dimension "number of optimal paths" was divided into two categories: tasks with one optimal path were defined as "Simple," while those with more than one optimal path were defined as "Complex."

[Figure 1 to be placed here]

\subsection{Analysis}

To answer RQ1, McNemar's two-tailed exact binomial test for paired nominal data in 2 $\mathrm{x} 2$ contingency tables was used to explore potential differences between the Android and GoLivePhone launcher for each task in terms of task success. To investigate potential differences in task efficiency, the Wilcoxon signed-ranks test with exact distribution was run due to non-normally distributed data. To answer RQ2, each task (of which there were twenty in all, when considering both tested launchers) was classified according to the UCIM.

\section{Results}

With reference to RQ1, the results indicate significant differences between the two launchers in three out of ten tasks in terms of task success (Table 2). Notably, for creating

\footnotetext{
${ }^{4}$ The steps on the optimal path could be also referred to as production rules according to the Cognitive Complexity Theory (Ziefle and Bay, 2005).
} 
contacts and changing the phone number of a contact, Android outperformed GoLivePhone, while the latter marginally outdistanced Android for setting a contact profile picture. Significant differences in task efficiency were observed in seven out of ten tasks. GoLivePhone was found to be more efficient when deleting a contact, sending a short message service (SMS) message to a number, sending a picture to a contact via email, and setting the profile picture of a contact. Conversely, Android was found to be more efficient for creating a contact, changing the phone number of a contact, and deleting an event reminder.

[Table 2 to be placed here]

To answer RQ2, we compared the expected and observed outcome for task success and task efficiency of both launchers (Table 3). The expected outcome of the two launchers was determined according to their position for a selected task in the UICM, whereas the observed outcome was assessed based on the performance of the two launchers in the usability test. We expected an outcome with no differences between the two launchers in terms of task success and efficiency for the tasks positioned within the same quadrant of the UICM for both tested launchers. For tasks positioned in two different quadrants of the UICM for each of the two launchers, we expected a better performance in terms of both metrics for the one with a less complex/simpler user interface for task execution.

[Table 3 to be placed here]

With reference to task success, nine out of ten observed outcomes were in line with expected outcomes. For instance, as expected, there were no differences between launchers' performance for the "call phone number" task, as this task is positioned in the same UICM quadrant ("Simple") for both launchers. The only divergence between the observed and expected outcomes was found for task "send picture to contact via email," 
where no significant differences were observed in task success between the launchers even though, based on the UICM, GoLivePhone was expected to outperform Android.

With reference to task efficiency, seven out of ten observed outcomes were in line with expected outcomes. For instance, there were no differences between the launchers' performance for creating an event reminder, as this task is positioned in the same UICM quadrant ("Complex") for both Android and GoLivePhone. For deleting a contact and sending an SMS message to a number, task efficiency was better on GoLivePhone, whereas Android was better for deleting an event reminder; however, no differences were expected for these three tasks according to the UICM.

\section{Discussion}

The purpose of this exploratory study was two-fold. First, it sought to compare the usability performance between a standard Android smartphone launcher and an agefriendly GoLivePhone launcher (RQ1). Second, it sought to investigate how the user interface complexity — an important aspect of age-friendly design —of the two launchers is related to their usability performance (RQ2). With reference to the first aim (RQ1), the performance of the Android and GoLivePhone launchers was significantly different in terms of task success for only three tasks. The differences between the launchers were, however, more pronounced in terms of task efficiency, indicating the slightly quicker overall successful execution of tasks using GoLivePhone.

Such mixed evidence led us to examine the relationship between the user interface complexity and the usability performance of the launchers. In general, the comparison of the observed and expected outcomes of usability tests based on the UICM suggests that higher user interface complexity leads to lower usability performance in terms of both task success and task efficiency. Nonetheless, we also identified a task in which lower 
user interface complexity was not associated with higher task success. Notably, in spite of GoLivePhone having a less complex interface structure according to the UICM, no significant differences were found between the two launchers. Such a result might be explained by a higher number of optimal paths for the completion of that task on Android. Tellingly, a higher number of alternative optimal paths generally increases the likelihood of task completion. At the same time, in such cases, task efficiency decreases, and this was also confirmed in our data, with a significant difference in efficiency in favor of GoLivePhone.

In addition, in terms of task efficiency, the observed outcomes were not in line with the expected outcomes for deleting contact and sending SMS messages. A potential explanation might be found in the design guidelines for age-friendly user interfaces on smartphones. They suggest that an interface should help an older user to focus on one task on the screen at a time instead of requiring the user to actively monitor two or more tasks (Silva et al., 2015). GoLivePhone better follows such recommendation because it has a larger number of different screens through which the user passes while solving the task on the optimal path. In addition, a post-test inspection of both launchers revealed that users conducted a smaller number of actions on the same screen (according to the number of steps on the optimal path) on GoLivePhone than on Android. Further, the higher efficiency of GoLivePhone for the tasks "delete contact" and "send SMS to number" might be explained by a higher ratio between the average number of different screens on the optimal path divided by number of actions required to successfully complete the task following the optimal path. For example, the optimal path for deleting a contact includes five taps and five different screens through which the user passes. Accordingly, the ratio between number of different screens and actions required is 1 . Conversely, the ratio for 
the same task on Android is 0.75 . The last deviation between the observed and expected outcomes was found for the task of deleting an event reminder, where Android outperformed GoLivePhone despite no difference being expected according to the UICM. A potential explanation could be related to participants' limited experience with and only occasional use of the calendar on a smartphone (Chen et al., 2013; Dolničar et al., 2016a; Lee, 2007). As participants in this study were predominantly Android users (88\%), it seems reasonable to assume that for many of them, it could be easier to cope with an unknown feature on a known interface than on an unknown one. Tellingly, the ability of older adults to learn how to use technology is, in general, lower than that of other age groups (Kelley and Charness, 1995; Marquié et al., 2002).

The results of this study must be considered in light of study's limitations. First, while a fairly large sample for summative usability testing was used (Lewis, 2012), the results may not generalize to a population level due to the non-random selection of participants. Second, the relatively large number of experienced and longstanding Android smartphone users in the sample might have led to an overestimation of the usability performance of the standard Android launcher. It could be that if the test had been performed on another group of older adults with less experience in using smartphones, the results could have been substantially different (presumably in favor of an age-friendly launcher). Hence, further research needs to consider the use of a more heterogeneous sample in that respect. Third, future investigations might also benefit from comparing a standard Android launcher with more than one age-friendly designed launcher. Finally, the restricted selection of the two usability metrics might also render the comparisons inappropriate for establishing norms. However, since task success and task efficiency have been widely considered valid objective measures of two central 
usability dimensions-effectiveness and efficiency, respectively (Ziefle and Bay, 2005) — our selection seems to be appropriate and relevant for the study's purposes.

Overall, our results reveal that at least among older smartphone users the two tested launchers had comparable effectiveness, whereas the age-friendly launcher marginally outperformed the standard Android smartphone interface in terms of task efficiency. Moreover, they confirm that reducing the user interface complexity in terms of the number of optimal paths and the optimal path length is a viable design strategy to improve the user experience of older adults with smartphones. This finding is promising not only for designing age-friendly launchers with basic and most frequently used smartphone features but also for delivering rehabilitation interventions to older adults via smartphone apps.

\section{Acknowledgments}

The authors would like to thank Lina Maria Setničar and Anja Tuš for their assistance in the data collection process. 


\section{References}

Albert W, Tullis T (2013). Measuring the User Experience: Collecting, Analyzing, and Presenting Usability Metrics. 2nd ed. Waltham, MA: Morgan Kaufmann.

Anderson M, Perrin A (2017). Tech Adoption Climbs Among Older Adults. Washington DC: Pew Research Center.

Arab F, Malik Y, Abdulrazak B (2013). Evaluation of PhonAge: An Adapted Smartphone Interface for Elderly People. In Human-Computer Interaction INTERACT 2013, Lecture Notes in Computer Science. Berlin: Springer; pp. $547-554$.

Balata J, Mikovec Z, Slavicek T (2015). KoalaPhone: touchscreen mobile phone UI for active seniors. J Multimodal User Interfaces 9, 1-11.

Chen K, Chan AHS, Tsang SNH (2013). Usage of mobile phones amongst elderly people in Hong Kong. Proc. Int MultiConference Eng Comput Sci 2013, 10161019.

Dicianno BE, Parmanto B, Fairman AD, Crytzer TM, Yu DX, Pramana G, et al. (2015). Perspectives on the Evolution of Mobile (mHealth) Technologies and Application to Rehabilitation. Phys Ther 95, 397-405.

Dolničar V, Berzelak J, Petrovčič A (2016a). Survey on the use of mobile phones among older adults in Slovenia: overview of frequency distributions and descriptive statistics. Ljubljana: Faculty of Social Sciences, Centre for Social Informatics.

Dolničar V, Šetinc M, Petrovčič A (2016b). Toward an age-friendly design of smartphone interfaces: the usability test of a launcher for older adults. Uporab Inform XXIV, 4-15. 
Doughty K, Williams G (2016). New models of assessment and prescription of smart assisted living technologies for personalised support of older and disabled people. J Assist Technol 10, 39-50.

Endsley MR (2011). Designing for Situation Awareness: An Approach to UserCentered Design. 2nd ed. Boca Raton, FL: CRC Press.

Fisk AD, Rogers WA, Charness N, Czaja SJ, Sharit J (2009). Designing for Older Adults: Principles and Creative Human Factors Approaches. 2nd ed. Boca Raton, FL: CRC Press.

Fox S, Duggan M (2013). Tracking for Health. Washington, DC: Pew Research Center.

Gandhi S, Chen S, Hong L, Sun K, Gong E, Li C, Yan LL, et al. (2016). Systematic Review/Meta-analysis: Effect of Mobile Health Interventions on the Secondary Prevention of Cardiovascular Disease: Systematic Review and Meta-analysis. Can J Cardiol 33, 219-231.

Holzinger A, Searle G, Nischelwitzer A (2007). On Some Aspects of Improving Mobile Applications for the Elderly. In: Proceedings of the 4th International Conference on Universal Access in Human Computer Interaction: Coping with Diversity, UAHCI’07. Berlin: Springer; pp. 923-932.

Hwangbo H, Yoon SH, Jin BS, Han YS, Ji YG (2013). A Study of Pointing Performance of Elderly Users on Smartphones. Int J Human-Computer Interact 29, 604-618.

ISO 9241-11 (2018). Ergonomics of human-system interaction - Part 11: Usability: Definitions and Concepts. Geneva: ISO.

Kelley C, Charness N (1995). Issues in training older adults to use computers. Behav Inf Technol 14, 107-120. 
Lee YS (2007). A Survey of Mobile Phone Use in Older Adults. Proc. Hum Factors Ergon Soc Annu Meet 51, 1-5.

Maddison R, Pfaeffli L, Whittaker R, Jiang Y, Carter K, Rawstorn J, et al. (2015). A mobile phone intervention increases physical activity in people with cardiovascular disease: Results from the HEART randomized controlled trial. Eur J Prev Cardiol 22, 701-709.

Marquié JC, Jourdan-Boddaert L, Huet N (2002). Do older adults underestimate their actual computer knowledge? Behav Inf Technol 21, 273-280.

Nielsen J, Budiu R (2012). Mobile Usability. Berkeley, CA, USA: New Riders.

Park LG, Beatty A, Stafford Z, Whooley MA (2016). Mobile Phone Interventions for the Secondary Prevention of Cardiovascular Disease. Prog Cardiovasc Dis 58, $639-650$.

Petrovčič A, Rogelj A, Dolničar V (2018a). Smart but not adapted enough: Heuristic evaluation of smartphone launchers with an adapted interface and assistive technologies for older adults. Comput Hum Behav 79, 123-136.

Petrovčič A, Taipale S, Rogelj A, Dolničar V (2018b). Design of Mobile Phones for Older Adults: An Empirical Analysis of Design Guidelines and Checklists for Feature Phones and Smartphones. Int J Human-Computer Interact 34, 251-264.

Plaza I, Martín L, Martin S, Medrano C (2011). Mobile Applications in an Aging Society: Status and Trends. J Syst Softw 84, 1977-1988.

Reyes A, Qin P, Brown CA (2018). A standardized review of smartphone applications to promote balance for older adults. Disabil Rehabil 40, 690-696.

Sergeev A (2010). User interfaces design. Efficiency. Available at: http://uidesigner.net/usability/efficiency.htm. [Accessed 10 May 2018]. 
Siegel C, Dorner TE (2017). Review article: Information technologies for active and assisted living - Influences to the quality of life of an ageing society. Int J Med $\operatorname{Inf} \mathbf{1 0 0}, 32-45$.

Silva PA, Holden K, Jordan P (2015). Towards a List of Heuristics to Evaluate Smartphone Apps Targeted at Older Adults: A Study with Apps that Aim at Promoting Health and Well-Being. In: 48th Hawaii International Conference on System Sciences, HICSS 2015. Kauai, Hawaii: IEEE; pp. 3237-3246.

Sonderegger A, Sauer J (2010). The influence of design aesthetics in usability testing: Effects on user performance and perceived usability. Appl Ergon 41, 403-410. TechSmith (2018). Morae. Usability Test. Morae. Available at: https://www.techsmith.com/morae.html. [Accessed 10 May 2018].

Wong D, Wang QJ, Stolwyk R, Ponsford J (2017). Do Smartphones have the Potential to Support Cognition and Independence Following Stroke? Brain Impair 18, $310-320$.

Ziefle M (2002). The influence of user expertise and phone complexity on performance, ease of use and learnability of different mobile phones. Behav Inf Technol 21, $303-311$.

Ziefle M, Bay S (2005). How older adults meet complexity: Aging effects on the usability of different mobile phones. Behav Inf Technol 24, 375-389. 


\section{Tables}

Table 1. Testing scenario tasks.

\begin{tabular}{|c|c|c|}
\hline Task & Feature & Task description \\
\hline T1 & $\begin{array}{l}\text { Call and } \\
\text { contact }\end{array}$ & $\begin{array}{l}\text { Call the phone number } 015805380 . \text { When you hear ringing, end the } \\
\text { call. }\end{array}$ \\
\hline $\mathrm{T} 2$ & & Create new contact Helen Blunt with phone number 030456061. \\
\hline $\mathrm{T} 3$ & & Delete contact Alice Emerson. \\
\hline $\mathrm{T} 4$ & & Change phone number of contact Anna Spencer to 030456071 . \\
\hline T5 & SMS & $\begin{array}{l}\text { Send SMS message with content "Ok" to phone number } 040641177 . \\
\text { Send SMS message with content "I am coming" to contact Jane } \\
\text { Booker. }\end{array}$ \\
\hline $\mathrm{T} 7$ & Gallery & $\begin{array}{l}\text { In the gallery, find the photo of a house. Open the photo and send it to } \\
\text { contact Martha Davison. }\end{array}$ \\
\hline $\mathrm{T} 8$ & & Add the photo of a woman from the gallery to contact Lucy Parker. \\
\hline T9 & Calendar & $\begin{array}{l}\text { Create an event "Visit" for Friday, } 30 \text { June at } 3-4 \text { pm in the city } \\
\text { center. Set it as a one-time event without a reminder. }\end{array}$ \\
\hline $\mathrm{T} 10$ & & $\begin{array}{l}\text { Find and delete the event "Celebration," which should take place on } \\
\text { June } 28 .\end{array}$ \\
\hline
\end{tabular}


Table 2. Task success and task efficiency by launcher and task.

\begin{tabular}{|c|c|c|c|c|c|c|c|}
\hline \multirow[b]{2}{*}{ Task } & \multirow[b]{2}{*}{$\mathrm{n}^{\mathrm{a}}$} & \multicolumn{3}{|c|}{ Task success } & \multicolumn{3}{|c|}{ Task efficiency $^{\mathrm{c}}$} \\
\hline & & Android & GLP & $\mathrm{p}^{\mathrm{b}}$ & Android & GLP & $\mathrm{p}^{\mathrm{b}}$ \\
\hline Call phone number & 50 & .920 & .940 & $>.999$ & 0.045 & 0.048 & .587 \\
\hline Create contact & 50 & .760 & .380 & $<.001$ & 0.017 & 0.006 & $<.001$ \\
\hline Delete contact & 49 & .878 & .939 & .453 & 0.037 & 0.068 & $<.001$ \\
\hline $\begin{array}{l}\text { Change phone number } \\
\text { of contact }\end{array}$ & 49 & .857 & .612 & .002 & 0.026 & 0.013 & $<.001$ \\
\hline Send SMS to number & 50 & .720 & .860 & .118 & 0.014 & 0.019 & .026 \\
\hline Send SMS to contact & 49 & .857 & .857 & $>.999$ & 0.027 & 0.026 & .461 \\
\hline $\begin{array}{l}\text { Send picture to contact } \\
\text { via email }\end{array}$ & 48 & .563 & .646 & .523 & 0.010 & 0.020 & .005 \\
\hline $\begin{array}{l}\text { Set profile picture of } \\
\text { contact }\end{array}$ & 45 & .222 & .333 & .063 & 0.005 & 0.009 & .004 \\
\hline Create event reminder & 42 & .095 & .119 & $>.999$ & 0.001 & 0.001 & .469 \\
\hline Delete event reminder & 40 & .650 & .525 & .125 & 0.026 & 0.013 & .004 \\
\hline Totes. ${ }^{\text {a }}$ Number of pair & 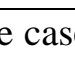 & $\operatorname{aries~} d$ & tas & als. ${ }^{\mathrm{b}} \mathrm{D}$ & ices & fican & K.1 \\
\hline
\end{tabular}


Table 3. Task success and task efficiency in terms of User Interface Complexity Matrix (UICM).

\begin{tabular}{|c|c|c|c|c|c|}
\hline \multirow{2}{*}{ Task } & \multicolumn{2}{|c|}{ User Interface Complexity Matrix (UICM) } & \multirow{2}{*}{$\begin{array}{l}\text { Expected } \\
\text { Outcome }^{b}\end{array}$} & \multirow{2}{*}{$\begin{array}{c}\text { Observed Outcome } \\
\text { TS }\end{array}$} & \multirow{2}{*}{$\begin{array}{c}\text { Observed Outcome } \\
\text { TE }\end{array}$} \\
\hline & Android & GLP & & & \\
\hline $\mathrm{T} 1$ & $\operatorname{Sim}(3), \operatorname{Sim}(1)^{\mathrm{a}}$ & $\operatorname{Sim}(3), \operatorname{Sim}(1)$ & nd & ns & ns \\
\hline $\mathrm{T} 2$ & $\operatorname{Sim}(4), \operatorname{Sim}(1)$ & $\operatorname{Com}(8), \operatorname{Com}(2)$ & Android & Android & Android \\
\hline $\mathrm{T} 3$ & $\operatorname{Sim}(4), \operatorname{Sim}(1)$ & $\operatorname{Sim}(5), \operatorname{Sim}(1)$ & nd & ns & GLP \\
\hline $\mathrm{T} 4$ & $\operatorname{Sim}(5), \operatorname{Sim}(1)$ & $\operatorname{Com}(8), \operatorname{Sim}(1)$ & Android & Android & Android \\
\hline T5 & $\operatorname{Sim}(4), \operatorname{Sim}(1)$ & $\operatorname{Sim}(5), \operatorname{Sim}(1)$ & nd & ns & GLP \\
\hline T6 & $\operatorname{Sim}(4), \operatorname{Sim}(1)$ & $\operatorname{Sim}(4), \operatorname{Sim}(1)$ & nd & ns & ns \\
\hline $\mathrm{T} 7$ & $\operatorname{Com}(6), \operatorname{Com}(7)$ & $\operatorname{Com}(6), \operatorname{Sim}(1)$ & GLP & ns & GLP \\
\hline $\mathrm{T} 8$ & $\operatorname{Com}(8), \operatorname{Com}(4)$ & $\operatorname{Com}(7), \operatorname{Sim}(1)$ & GLP & GLP & GLP \\
\hline T9 & $\operatorname{Com}(7), \operatorname{Com}(2)$ & Com (14), Com (2) & nd & ns & ns \\
\hline $\mathrm{T} 10$ & $\operatorname{Com}(6), \operatorname{Com}(4)$ & $\operatorname{Com}(7), \operatorname{Com}(2)$ & nd & ns & Android \\
\hline
\end{tabular}

Notes. ${ }^{\text {a }}$ Task T1 was assessed as simple according to both UICM dimensions. "Sim (3)" refers to simple in terms of the length of the optimal path, which requires three actions for task completion, whereas the second dimension, "Sim (1)," means that a task is defined as simple in terms of the number of optimal paths, with only one optimal path for a given task completion. ${ }^{\mathrm{b}}$ Instances in which expected outcomes are confirmed by observed outcomes are marked in bold. $\mathrm{Nd}=$ no differences in expected outcome; Ns = non-significant differences in observed outcomes at $\mathrm{p}>.1$ level; $\mathrm{TS}=$ task success; $\mathrm{TE}=$ task efficiency. GLP = GoLivePhone. 


\section{Figure}

Figure 1. User Interface Complexity Matrix.

Number of optimal paths

$=1 \quad>1$

Length of optimal path $\leq 5 \quad$ Simple-Simple Simple-Complex

> 5 Complex-Simple Complex-Complex 